\title{
TEMPAT SAMPAH PINTAR DENGAN NOTIFIKASI BERBASIS IOT
}

\author{
Yohanes Bowo Widodo ${ }^{1}$ \\ Prodi Teknik Informatika \\ Universitas MH. Thamrin \\ ybowowidodo@gmail.com
}

\author{
Tata Sutabri ${ }^{2}$ \\ Fakultas Teknologi Informasi \\ Universitas Respati Indonesia \\ tata.sutabri@gmail.com
}

\author{
Leo Faturahman ${ }^{3}$ \\ Prodi Teknik Informatika \\ Universitas MH. Thamrin \\ komengdewek@gmail.com
}

\begin{abstract}
Abstrak - Pengelolaan sampah menjadi salah satu faktor yang mempengaruhi terciptanya lingkungan yang bersih dan sehat. Sampah yang dibiarkan terlalu lama menumpuk dan pengambilan sampah yang tidak teratur menjadi masalah yang sering terjadi. Proses pengumpulan sampah yang dilakukan dengan melakukan pemeriksaan tempat penampungan sampah satu persatu menyebabkan pekerjaan yang tidak efektif dan efisien karena menghabiskan banyak waktu, tenaga dan biaya. Permasalahan yang dikaji dalam penelitian ini yaitu cara membangun kotak sampah pintar menggunakan sensor ultrasonik berbasis mikrokontroler WeMos D1 Mini yang dapat mendeteksi apakah kotak sampah telah penuh atau belum. Penelitian ini bertujuan untuk membuat perancangan purwarupa deteksi isi kotak sampah menggunakan sensor ultrasonik, apabila isi kotak sampah telah mencapai $\geq 80 \%$ maka sistem akan mengirimkan pemberitahuan berupa e-mail kepada petugas kebersihan yang akan mengumpulkan sampah.
\end{abstract}

Keywords: Tempat sampah pintar, mikrokontroler, ultrasonik

\section{Pengantar}

Pada dasarnya internet of things adalah sebuah konsep untuk memaksimalkan fungsi konektivitas internet. Awalnya internet hanya menghubungkan antara manusia dengan manusia, kemudian berkembang menjadi manusia dengan benda, maupun benda dengan benda. Sejarah awal dari dikembangkannya Internet adalah untuk menghubungkan komputer dan komputer. Komputer tersebut berisi tentang data data yang diolah manusia, dengan kata lain Internet pada saat itu menghubungkan antara manusia dengan manusia, sehingga manusia dapat saling bertukar informasi dan sumber daya. Seiring dengan berkembangnya Teknologi, Manusia ingin mengembangkan fungsi internet menjadi penghubung manusia dengan benda. Interaksi Internet Bukan lagi antara manusia dengan komputer, namun manusia dengan TV, kulkas, mesin cuci, kendaraan pribadi, dan apapun bendanya. Semua menggunakan Internet. Hal inilah yang menjadi dasar berkembangnya IoT (Internet of Things). Internet of Things merupakan perkembangan keilmuan yang sangat menjanjikan untuk mengoptimalkan kehidupan berdasarkan sensor cerdas dan peralatan pintar yang bekerjasama melalui jaringan internet.(Jensen \& Durham, 2017)
Dalam penelitian ini dikembangkan teknologi yang digunakan dalam memelihara kebersihan, dalam hal ini adalah tempat sampah pintar. Tempat sampah pintar ini memiliki sensor ultrasonik yang dapat mengukur tingkat penuhnya tempat sampah, dan dapat memberikan notifikasi kepada petugas kebersihan apabila sampah suda penuh, yaitu pada ketinggian lebih dari $80 \%$ ketinggian tempat sampah. Berdasarkan notifikasi yang diterima, petugas pengelola sampah dapat mengetahui tempat sampah mana yang sudah harus ditangani, yaitu dengan memindahkan sampah yang sudah hampir penuh ke tempat penampungan yang ditentukan.

\section{METODE PENELITIAN}

Tujuan dari pembuatan sebuah sistem otomatisasi pemberitahuan pada kotak sampah adalah untuk memberikan pemberitahuan apabila kotak sampah telah penuh sehingga mencegah terjadinya penumpukan sampah yang menjadi penyebab terjangkitnya bibit penyakit. Penelitian ini dilakukan dengan empat tahap proses yaitu analisis masalah dan kebutuhan, perancangan dan implementasi, serta pengujian. Pada bagian ini diuraikan Analisis masalah dan kebutuhan, sedangkan perancangan dan implementasi serta pengujian diuraikan dalam sub judul tersendiri.

\section{Analisis masalah dan kebutuhan}

Beberapa permasalahan atau kekurangan yang umumnya terjadi pada pengelolaan sampah adalah sebagai berikut :

1. Pengambilan sampah yang sering terlambat mengakibatkan sampah menumpuk.

2. Kegiatan pengumpulan sampah oleh petugas kebersihan yang tidak efisien menghabiskan banyak waktu dan energi untuk memeriksa kotak sampah.

3. Mengurangi resiko sampah membusuk.

WeMos D1 mini dipilih karena cukup mudahnya pengoperasian dan kompatibilitas terhadap bermacam - macam sensor yang tersedia. IDE yang cukup ramah terhadap pengguna, serta banyaknya tutorial dalam forum - forum di internet bagi para pengguna mikrokontroler WeMos D1 mini. Hal ini tentu saja membantu dalam pembuatan alat.

Fungsi yang dibutuhkan antara lain: 
1. Dapat melakukan pemeriksaan terhadap kotak sampah apabila sudah penuh.

2. Dapat mengirimkan pemberitahuan (notifikasi) bahwa kotak sampah sudah penuh.

Tahap analisis kebutuhan masukan menentukan masukan apa yang sesuai dengan kondisi lingkungan. Masukan yang dibutuhkan adalah data volume dari kotak sampah yang diperoleh dari modul sensor ultrasonik.

Analisis kubutuhan luaran, pada penelitian ini ialah mampu mengirimkan pemberitahuan penuhnya kotak sampah kepada perangkat yang dituju.

Analisis kebutuhan perangkat keras mengidentifikasi perangkat apa saja yang dibutuhkan. Berikut daftar komponen yang digunakan:

Perangkat komputer

WeMos D1 Mini

Modul sensor Ultrasonik

Kabel USB

Kabel jumper

Baterai

Lampu led kecil

Resistor

Saklar on off

Analisis Kebutuhan Perangkat Lunak mengidentifikasi perangkat lunak yang dibutuhkan yaitu sebagai berikut:

Sistem Operasi Windows, sistem operasi ini dibutuhkan untuk membangun kotak sampah pintar dengan menggunakan mikrokontroler WeMos D1 Mini.

Arduino Uno IDE. Software arduino ini digunakan untuk memprogram Arduino Uno agar dapat terkoneksi dengan sensor dan modul yang dibutuhkan dan mengunggah kode program ke dalam perangkat WeMos D1 Mini .

Blynk (platform) bkynk adalah platform untuk aplikasi OS Mobile (iOS dan Android) yang bertujuan untuk kendali modul Wemos D1 mini.

\section{TOOLS}

\section{A. WeMos D1 Mini}

Wemos merupakan salah satu modul board yang dapat berfungsi dengan arduino khususnya untuk project yang mengusung konsep IOT. Wemos dapat running standalone tanpa perlu dihubungkan dengan mikrokontroler, berbeda dengan modul wifi lain yang masih membutuhkan mikrokontroler sebagai pengrontrol atau otak dari rangkaian tersebut, wemos dapat running stand-alone karena didalamnya sudah terdapat CPU yang dapat diprogram melalui serial port atau via OTA serta transfer program secara wireless.

Wemos D1 mini (Gambar 1) ini memiliki dua sisi, sisi atas (gambar sebelah kiri) dan sisi bawah (gambar sebelah kanan). Penggunaan kedua sisi inilah yang membuat Wemos D1 mini tampil lebih ringkas dan sekaligus terkecil diantara pesaingnya.

Pada sisi atas terdapat ESP8266 yang berwarna hitam. Selain itu ada pin yang bertuliskan TX, RX, D1, dan lain sebagainya. Pin-pin ini dapat diprogram untuk menghubungkan program komputer dengan lingkungan sekitar. Di sisi samping kanan terdapat tulisan reset dan ada tombol kecil. Tembol reset ini berguna untuk me-reset microcontroller untuk booting kembali, seperti tombol reset di pc.

Pada sisi bawah ada komponen elektronik yang utamanya adalah chip agar komputer (linux/windows/mac) seketika mendeteksi board ini saat dihubungkan melalui kabel usb.

Terdapat pula pengatur tegangan listrik yang melindungi sleluruh komponen Wemos D1 mini agar tetap mendapat tegangan dan arus listrik yan sesuai dengan kebutuhannya.
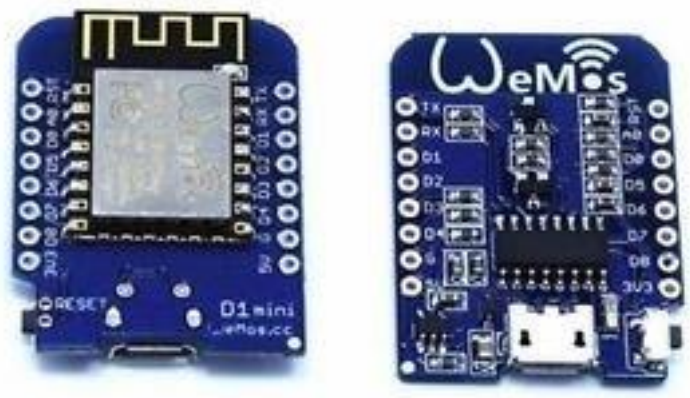

Gambar 1. sisi atas dan bawah Wemos D1 mini

\section{B. Arduino IDE}

IDE merupakan kependekan dari Integrated Developtment Enviroenment, yaitu merupakan lingkungan terintegrasi yang digunakan untuk melakukan pengembangan. Disebut sebagai lingkungan karena melalui software inilah Arduino diprogram untuk melakukan fungsi-fungsi yang ditulis melalui sintaks Bahasa pemrograman. Arduino menggunakan bahasa pemrograman sendiri yang menyerupai bahasa C. Bahasa pemrograman Arduino (Sketch) sudah dilakukan perubahan untuk memudahkan pemula dalam melakukan pemrograman dari bahasa aslinya. Sebelum dijual ke pasaran, IC mikrokontroler Arduino telah ditanamkan suatu program bernama Bootlader yang berfungsi sebagai penengah antara compiler Arduino dengan mikrokontroler.

Arduino IDE dibuat dari bahasa pemrograman JAVA. Arduino IDE juga dilengkapi dengan library $\mathrm{C} / \mathrm{C}++$ yang biasa disebut Wiring yang membuat operasi input dan output menjadi lebih mudah. Arduino IDE ini dikembangkan dari software processing yang dirombak menjadi Arduino IDE khusus untuk pemrograman dengan Arduino.

Program yang ditulis dengan menggunaan Arduino Software (IDE) disebut sebagai sketch. Sketch ditulis dalam suatu editor teks dan disimpan dalam file dengan ekstensi .ino. Teks editor pada Arduino Software memiliki fitur seperti cutting/paste dan 
seraching/replacing sehingga memudahkan dalam menulis kode program.

Pada Software Arduino IDE, terdapat semacam message box berwarna hitam yang berfungsi menampilkan status, seperti pesan error, compile, dan upload program. Di bagian bawah paling kanan Sotware Arduino IDE, menunjukan board yang terkonfigurasi beserta COM Ports yang digunakan.

\section{Blink}

BLYNK adalah platform untuk aplikasi OS Mobile (iOS dan Android) yang bertujuan untuk kendali module Arduino, Raspberry Pi, ESP8266, WEMOS D1, dan module sejenisnya melalui Internet.

Aplikasi ini merupakan wadah kreatifitas untuk membuat antarmuka grafis untuk proyek yang akan diimplementasikan hanya dengan metode drag and drop widget.

Penggunaannya sangat mudah. Pengaturan semuanya dapat dikerjakan dalam waktu kurang dari 5 menit. Blynk tidak terikat pada papan atau module tertentu. Dari platform aplikasi inilah dapat melakukan pengontrolan apapun dari jarak jauh, dimanapun kita berada dan waktu kapanpun. Dengan catatan terhubung dengan internet dengan koneksi yang stabil dan inilah yang dinamakan dengan sistem Internet of Things (IOT).

\section{Sensor Ultrasonik HC-SR04}

Sensor ultrasonik adalah sensor yang mengeluarkan gelombang suara pada frekuensi ultrasonik dan menangkap kembali pantulan gelombang tersebut. Sensor ini berguna untuk mendeteksi jarak antara posisi dengan benda apapun yang ada di depannya. Sensor ultrasonik kerap digunakan pada aplikasi robotik untuk membuat obstacle avoiding robot.

Sensor ultrasonik berkode HC-SR04 ini memiliki 4 buah kaki masing-masing dengan label Vcc, Trig, Echo, dan Gnd. Vcc artinya sensor ini membutuhkan tegangan tambahan untuk beroprasi, besarnya 5 volt. Trig adalah kaki yang digunakan untuk $\mathrm{T}$, sedangkan kaki Echo bertanggung jawab untuk menangkap glombang yang dipantulkan. Gnd adalah kutub negatif untuk sensor.

HC-SR04 adalah modul ultrasonik yang menyediakan fungsi pengukuran non-kontak $2 \mathrm{~cm}$ sampai $400 \mathrm{~cm}$. Ketepatan pengukuran jarak mencapai $3 \mathrm{~mm}$.

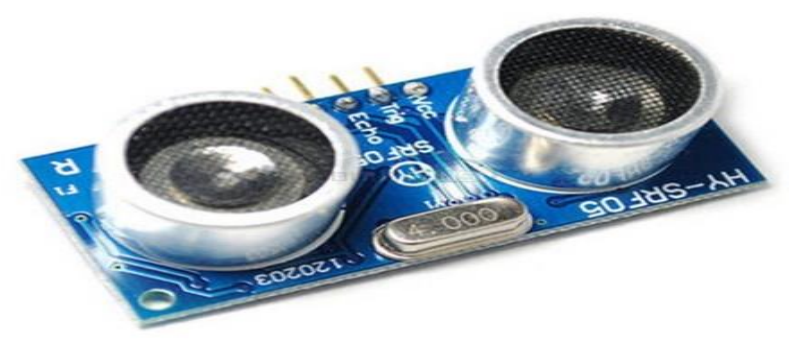

Gambar 2. Sensor Ultrasonik HC-SR04
Pada sensor ultrasonik, gelombang ultrasonik dibangkitkan melalui sebuah alat yang disebut dengan piezoelektrik dengan frekuensi tertentu. Piezoelektrik ini akan menghasilkan gelombang ultrasonik (umumnya berfrekuensi $40 \mathrm{kHz}$ ) ketika sebuah osilator diterapkan pada benda tersebut. Secara umum, alat ini akan menembakkan gelombang ultrasonik menuju suatu area atau suatu target. Setelah gelombang menyentuh permukaan target, maka target akan memantulkan kembali gelombang tersebut. Gelombang pantulan dari target akan ditangkap oleh sensor, kemudian sensor menghitung selisih antara waktu pengiriman gelombang dan waktu gelombang pantul diterima (Gambar 3).
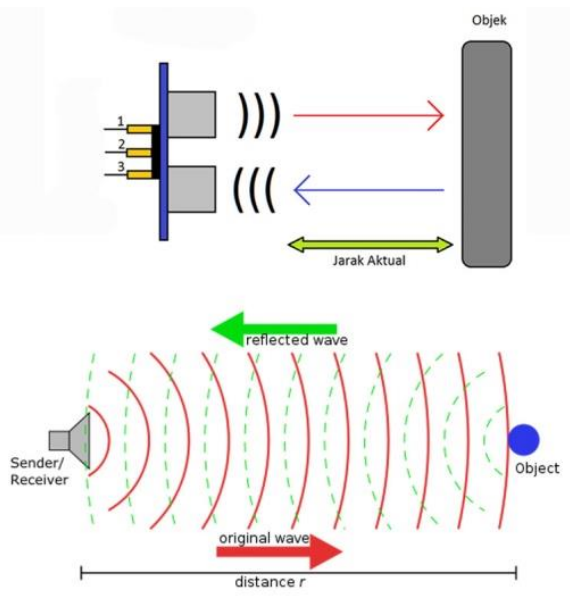

Gambar 3. Cara kerja sensor ultrasonik

Secara detail, cara kerja sensor ultrasonik adalah sebagai berikut:

Sinyal dipancarkan oleh pemancar ultrasonik dengan frekuensi tertentu dan dengan durasi waktu tertentu. Sinyal tersebut berfrekuensi diatas $20 \mathrm{kHz}$. Untuk mengukur jarak benda (sensor jarak), frekuensi yang umum digunakan adalah $40 \mathrm{kHz}$.

Sinyal yang dipancarkan akan merambat sebagai gelombang bunyi dengan kecepatan sekitar $340 \mathrm{~m} / \mathrm{s}$. Ketika menumbuk suatu benda, maka sinyal tersebut akan dipantulkan oleh benda tersebut.

Setelah gelombang pantulan sampai di alat penerima, maka sinyal tersebut akan diproses untuk menghitung jarak benda tersebut. Jarak benda dihitung berdasarkan rumus :

$$
\mathrm{S}=340 . \mathrm{t} / 2
$$

Dimana S merupakan jarak antara sensor ultrasonik dengan benda (bidang pantul), dan $\mathrm{t}$ adalah selisih antara waktu pemancaran gelombang oleh transmitter dan waktu ketika gelombang pantul diterima receiver.

Sensor ultrasonik digunakan untuk Mengetahui tempat sampah penuh atau tidak berdasarkan jarak ketinggian. Yaitu dengan mengukur jarak dari sensor ultrasonik menuju permukaan tempat sampah, jika tempat sampah kosong maka pembacaan sensor ultrasonik akan semakin jauh, sementara jika 
tempat sampah terisi pembacaan sensor ultrasonik akan semakin dekat.

\section{RANCANGAN DAN IMPLEMENTASI}

Tahap pertama yang dilakukan adalah melakukan perancangan perangkat keras dengan mengintegrasikan seluruh perangkat yang sudah di siapkan yaitu sensor yang dibutuhkan, modul, dan WeMos D1 Mini itu sendiri. Pada Gambar 4 adalah skema dari rangkaian perangkat keras.

Sensor ultrasonik digunakan untuk mendeteksi suatu benda atau objek pada jarak $3 \mathrm{~cm}-3 \mathrm{~m}$. Prinsip kerja sebuah modul sensor ultrasonik (PING) yaitu mendeteksi objek dengan cara mengirimkan gelombang ultrasonik dan kemudian menerima pantulan gelombang tersebut. PING akan mengirimkan gelombang ultrasonik ketika ada pulse trigger dari mikrokontroler (Pulse high selama $5 \mu \mathrm{S}$ ). Gelombang ultrasonik dengan frekuensi sebesar $40 \mathrm{KHz}$ akan dipancarkan selama $200 \mu \mathrm{S}$. Gelombang ini akan merambat di udara dengan kecepatan $344.424 \mathrm{~m} /$ detik (atau $1 \mathrm{~cm}$ setiap 29.034 $\mu \mathrm{S}$ ), mengenai objek untuk kemudian terpantul kembali ke PING. Selama menunggu pantulan, PING akan menghasilkan sebuah pulse. Pulse ini akan berhenti (low) ketika gelombang pantulan terdeteksi oleh PING. Oleh karena itu, lebar pulse tersebut dapat merepresentasikan jarak antara PING dengan objek.

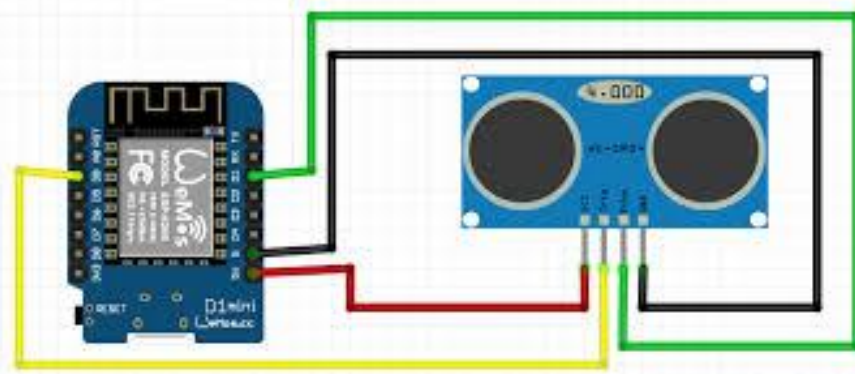

Gambar 4. WeMos D1 dan Sensor Ultrasonik

Flowchart pada Gambar 5 menjelaskan alur program yang dibuat dalam bentuk grafis agar dapat memahami logika proses yang dibuat. Flowchart tersebut menjelaskan alur bagaimana program pada Arduino Uno berjalan. Proses pertama adalah kode program akan memberikan perintah kepada sensor ultrasonik untuk mengirimkan pulse sinyal, kemudian pantulan sinyal yang diterima oleh sensor ultrasonik akan dihitung untuk mendapatkan data masukan berupa persentase kapasitas kotak sampah yang telah terisi. Jika persentase yang didapatkan $\geq 80 \%$ terisi maka program akan memberikan perintah kepada WeMos D1 untuk mengirimkan pemberitahuan (notifikasi) bahwa kotak sampah telah penuh. Kemudian, apabila persentase yang didapatkan <80\% maka akan kembali kepada proses awal.

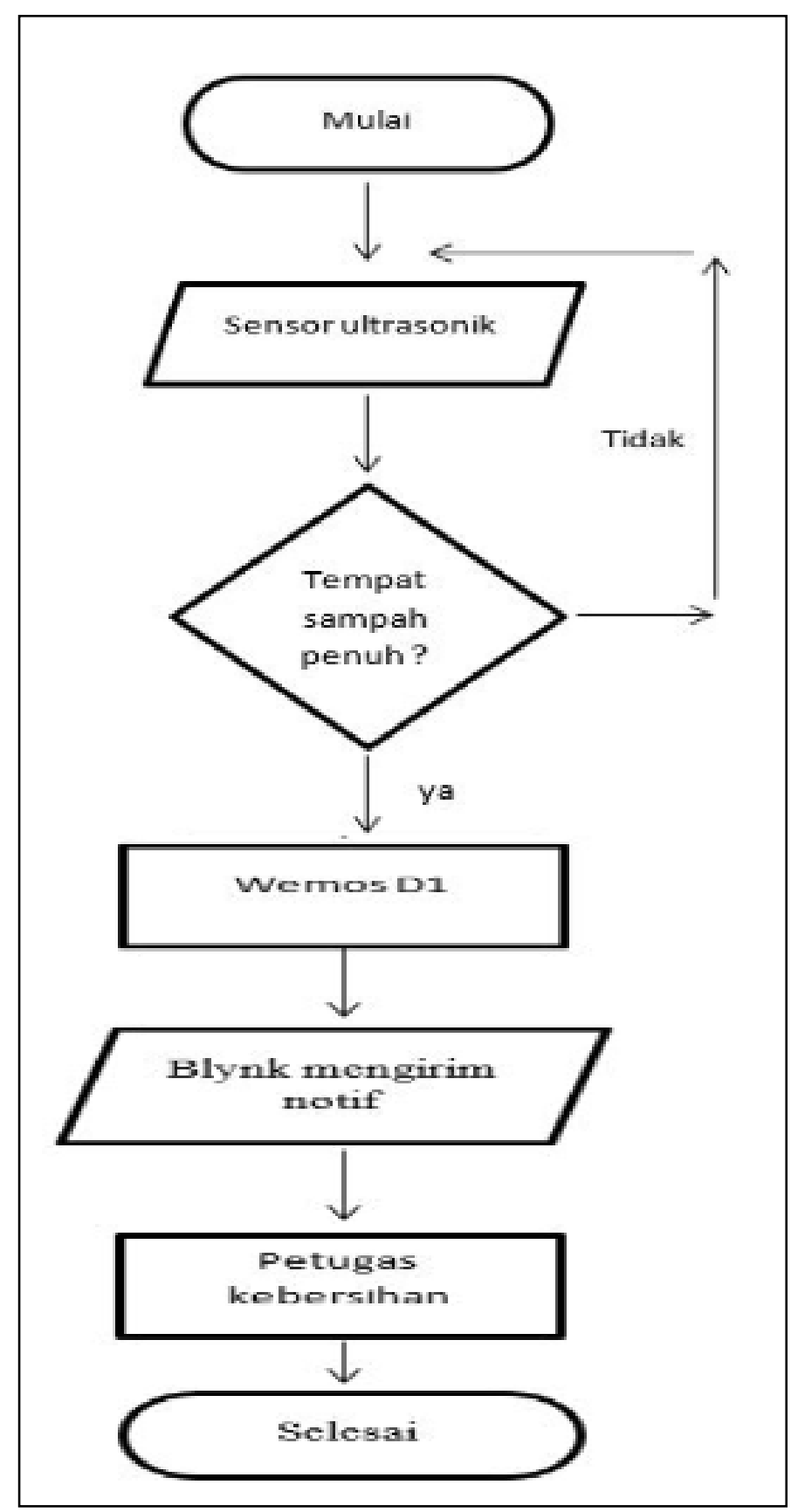

Gambar 5. Flowchart alur program

Proses perangkaian alat diawali dengan menghubungkan antara mikrokontroler WeMos D1 mini dengan sensor ultrasonik yang digunakan. Sensor ultrasonik dihubungkan menggunakan kabel jumper menuju ke WeMos D1 mini. Pin yang digunakan untuk menghubungkan sensor dengan Arduino Uno ada 4 yaitu pin (VCC) sebagai arus tegangan positif dari sensor ultrasonik menuju ke pin 5v pada WeMos D1, kemudian pin (GND) sebagai arus tegangan negative dari sensor ultrasonik menuju pin (GND) pada WeMos D1, pin (TRIG) pada sensor ultrasonik 
yang berfungsi sebagai pemancar gelombang suara ultrasonik dihubungkan dengan pin (D6) pada WeMos D1, pin (ECHO) pada sensor ultrasonik yang berfungsi sebagai penerima pantulan gelombang ultrasonik yang ditembakkan oleh pin (TRIG) dihubungkan menggunakan kabel jumper menuju ke pin (D5) WeMos D1 (lihat Gambar 6).

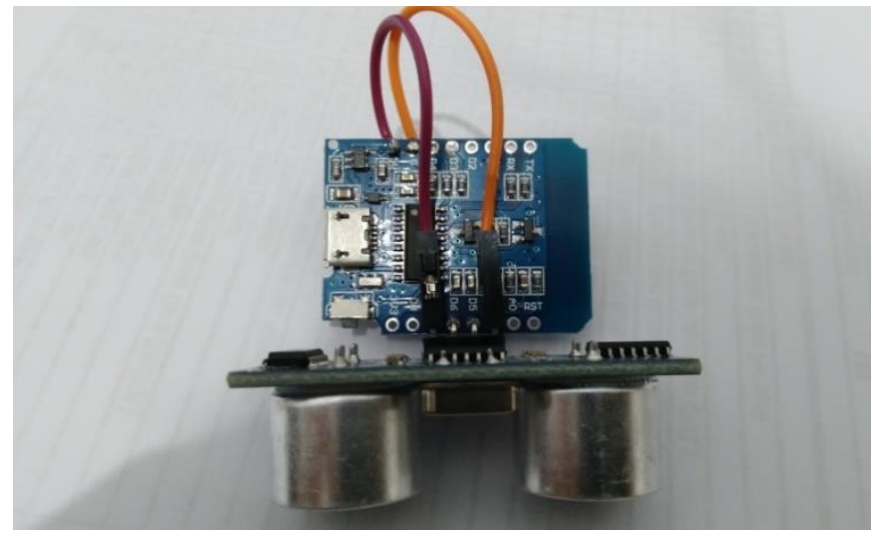

Gambar 6. Rangkaian WeMos dengan sensor ultrasonik

Setelah WeMos dan sensor ultrasonik telah terpasang selanjutnya adalah memasangkan lampu LED yang sudah dirangkai menggunakan resistor 220 dengan kutub negatif dihubungkan pada pin $5 \mathrm{v}$ sedangkan kutub positif dihubungkan pada (D8). Ini ditunjukan pada Gambar 7.

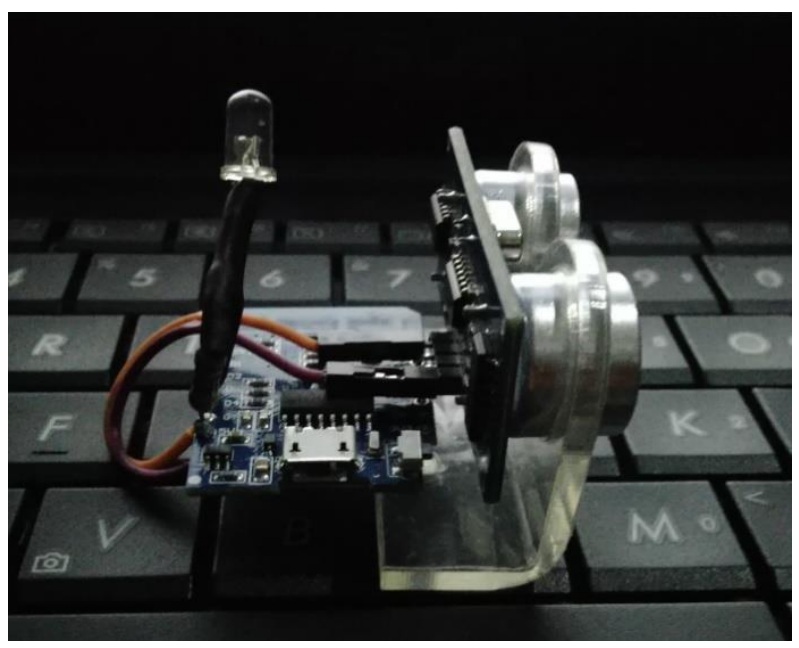

Gambar 7. Rangkaian lampu LED dengan WeMos dan sensor ultrasonik

Selanjutnya adalah meletakan sensor bersamaan dengan WeMos pada atas tempat sampah sebagaimana terlihat pada Gambar 8.

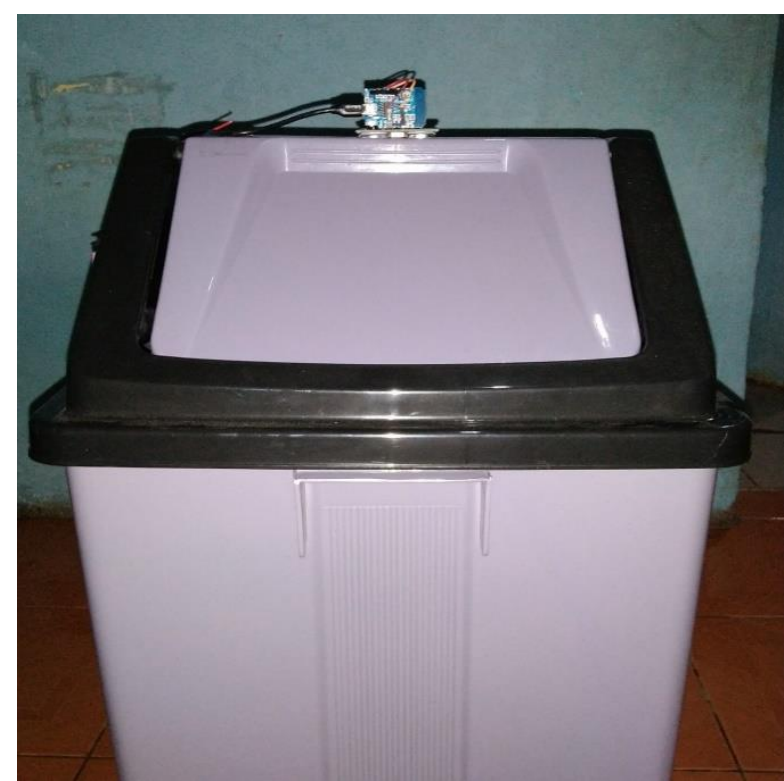

Gambar 8. Rangkaian lampu LED WeMos dan ultrasonik pada tempat sampah

Setelah rangkaian terpasang selanjutnya adalah menaruh power supply pada sisi samping tempat sampah, sebagaimana tergambar di Gambar 9.

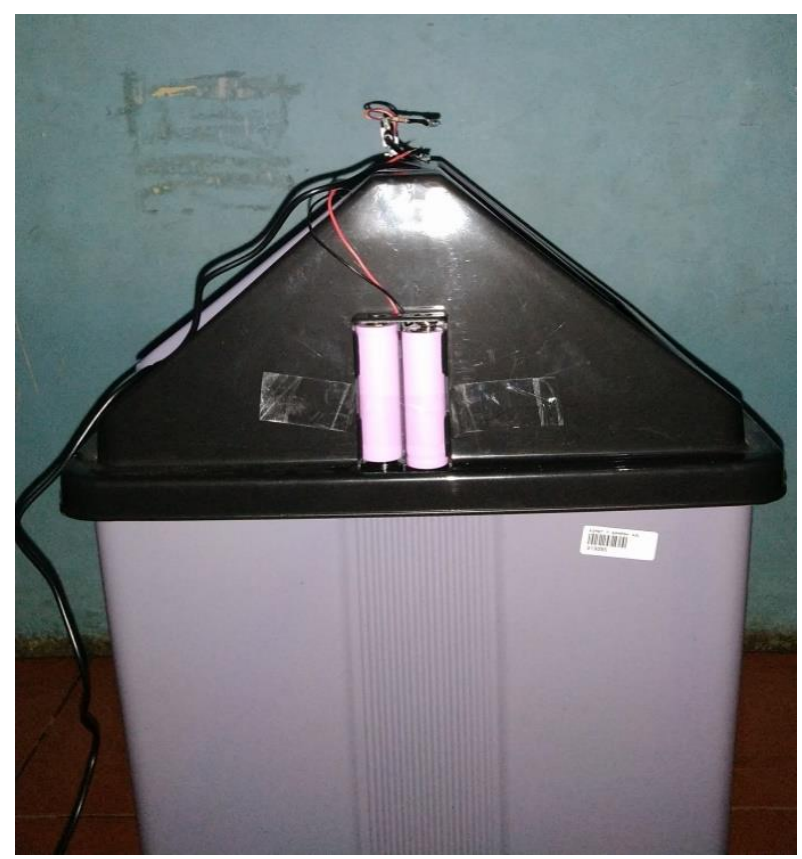

Gambar 9. Penempatan power supply pada tempat sampah

\section{PENGUJIAN}

Tahap pengujian sistem adalah tahap dimana setelah semua komponen dirangkai dan sistem siap beroperasi. Pengujian sistem dilakukan dengan tujuan agar mengetahui apakah sistem bekerja sesuai dengan keinginan atau tidak. Dalam pengujian sistem ini pula dapat diketahui kelebihan dan kekurangan dari sistem yang dibuat. 
Sebelum dilakukannya pengujian perlu dilakukan cek pada pemasangan kabel jumper yang menghubungkan semua komponen pada mikrokontroler. Pengujian dilakukan dengan melakukan percobaan pengisian kotak sampah dari kondisi kosong hingga penuh. Pengecekan terhadap posisi letak dari sensor ultrasonik juga harus diperhatikan agar menghasilkan keluaran yang akurat dan dipastikan bahwa sensor sudah terhubung dengan baik.

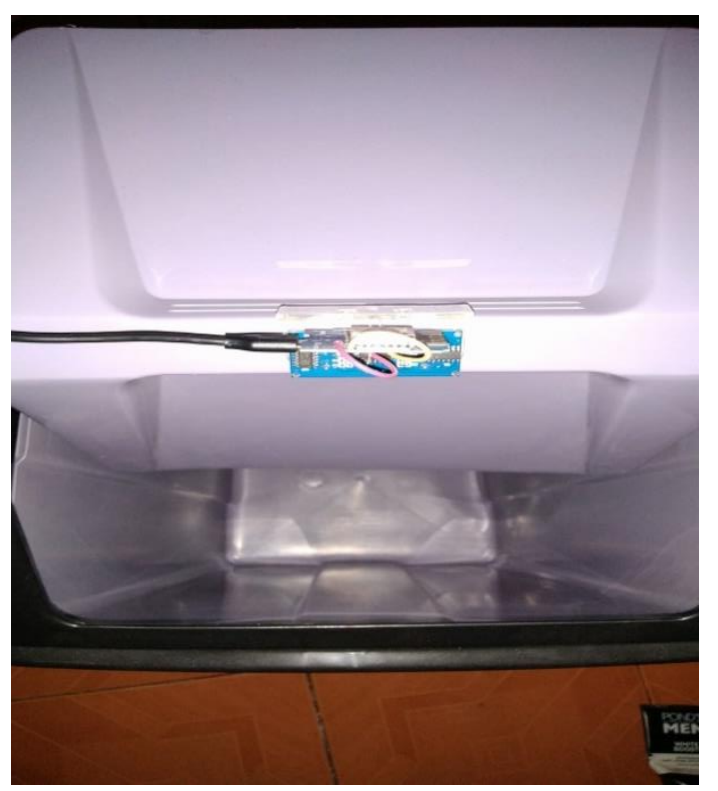

Gambar 10. Tempat sampah dalam keadaan kosong

Gambar 10 menunjukkan kotak sampah dalam kondisi kosong dan sensor ultrasonik telah terpasang dengan baik dan benar pada bagian tutup kotak sampah. Setelah memastikan kotak sampah dalam kondisi kosong selanjutnya menjalankan kode program untuk melihat tinggi yang dihasilkan oleh sensor ultrasonik.

Gambar 11 menunjukkan bahwa kotak sampah telah diisi, dan sistem menunjukkan tinggi sampah sudah mencapai $26 \mathrm{~cm}$ (terlihat pada Gambaar 12).Akan dilanjutkan sampai mencapai $40 \mathrm{~cm}$. Jika sudah mencapai $40 \mathrm{~cm}$ maka blynk akan mengirimkan notifikasi melalui email.

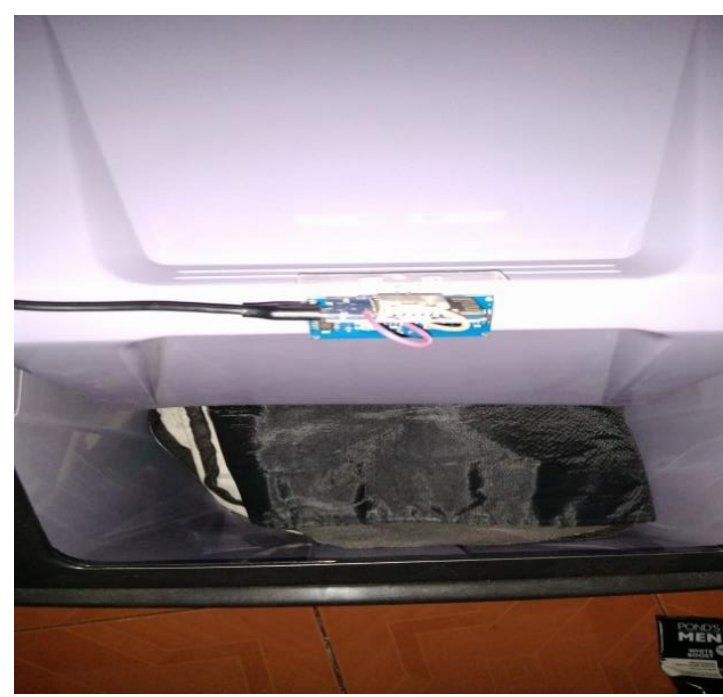

Gambar 11. Tempat sampah dalam keadaan terisi

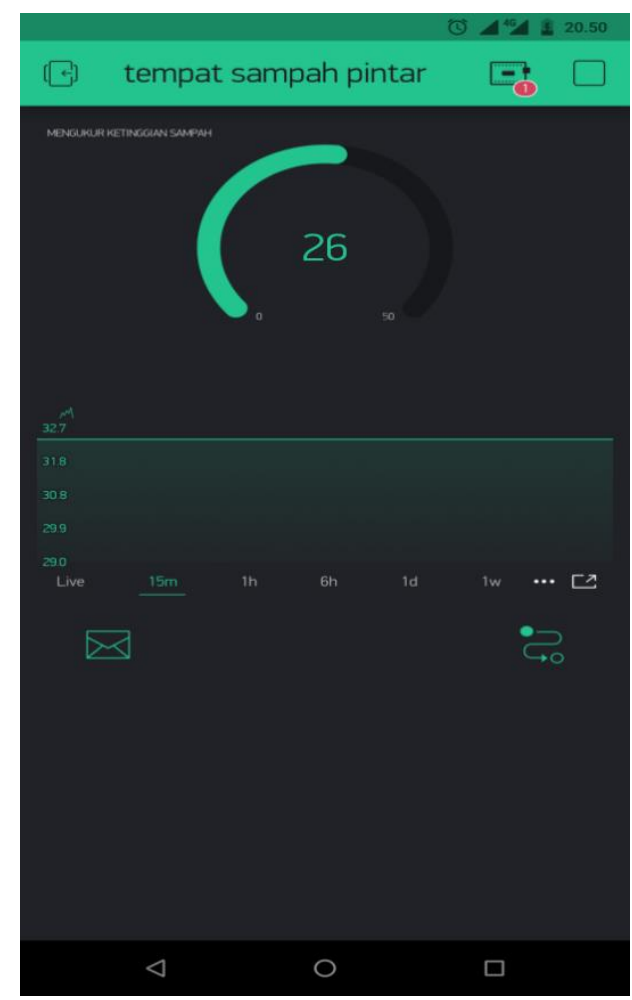

Gambar 12. Tempat sampah dalam keadaan terisi $26 \mathrm{~cm}$ terdeteksi oleh sistem 


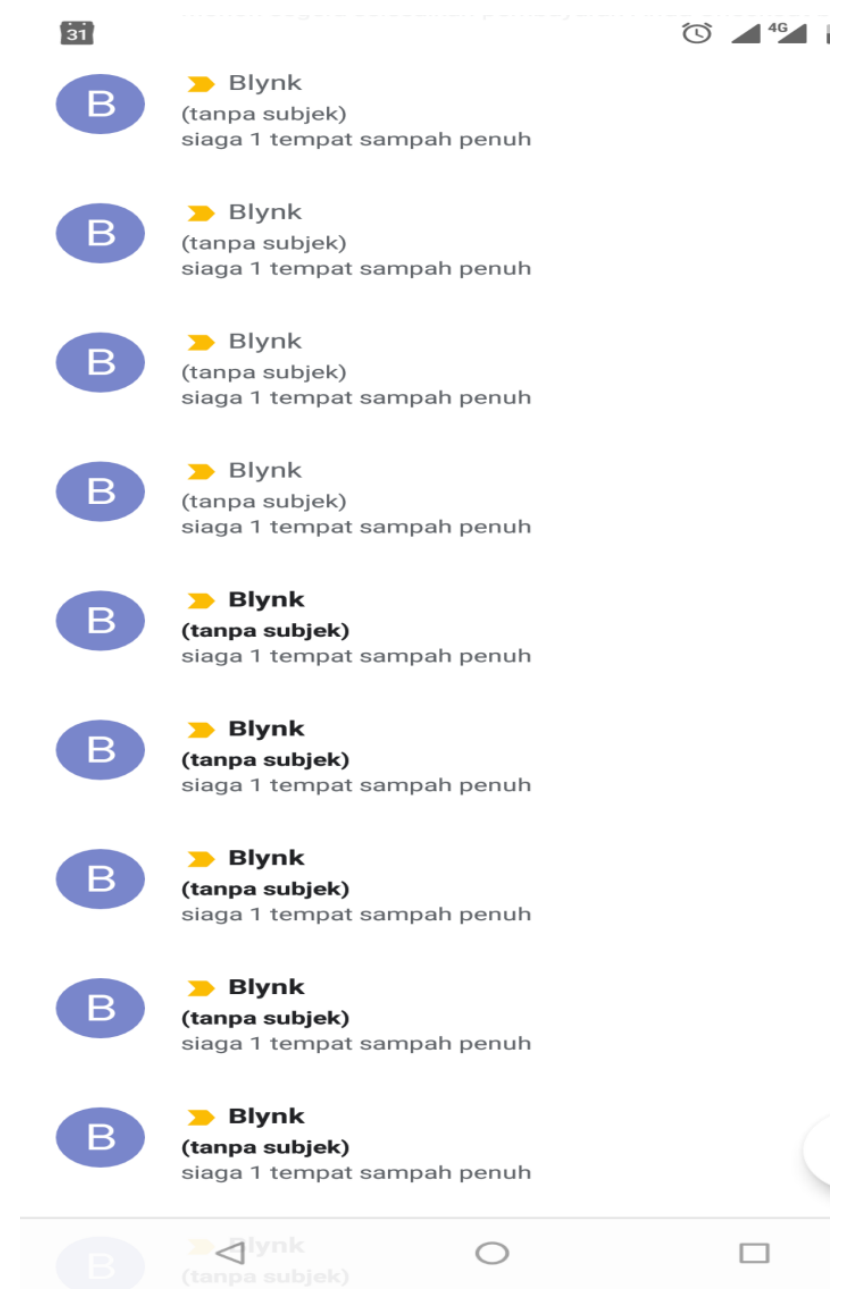

Gambar 13 Notifikasi e-mail

Gambar 13 menunjukan notifikasi bahwa tempat sampah telah penuh. Pengujian yang dilakukan berjalan dengan baik karna memiliki sinyal yang kuat dan dalam kondisi cuaca yang baik.

\section{ANALISIS}

Dari tahapan pengujian sebelumnya telah dilakukan beberapa tahapan utntuk mengetahui bagaimana sistem berjalan. Dengan melihat bagaimana sistem berjalan maka dapat dianalisis kelebihan dan kekurangan dari sistem ini.

Kelebihan Sistem :

1. Pemberitahuan melalui e-mail lebih efisien karna tidak diperlukannya pengontrolan sampah secara manual.

2. Mikrokontroler digunakan agar lebih mudah untuk dikembangkan di kemudian hari.

3. Sistem dapat digunakan pada berbagai macam tempat sampah.

4. Penggunaan hotspot dapat mengcover beberapa tempat sampah.

Kekurangan Sistem :

1. Alat masih berupa purwarupa jadi masih perlu banyak perbaikan, karena masih ada kesalahan dalam pendeteksian volume sampah.
2. pengiriman notifikasi terlambat jika sinyal lemah.

3. Pengukuran sampah masih dalam bilangan $\mathrm{cm}$.

\section{KESIMPULAN DAN SARAN}

Berdasarkan analisis proses hingga pengujian sistem, maka dapat ditarik kesimpulan sebagai berikut:

1. Tempat sampah pintar dengan notifikasi berbasis iot

2. berjalan dengan baik.

3. Notifikasi berhasil diterima dengan baik.

Saran untuk pengembangan kedepan terhadap sistem dan penelitian selanjutnya adalah sebagai berikut:

Dari perancangan alat tersebut masih banyak kekurangan yang dapat ditambahkan dalam perancangan selanjutnya. Untuk perancangan kedepan alat mengukur ketinggian sudah menggunakan bilangan $\%$, dan dapat menonaktifkan system secara otomatis apabila dibutuhkan

\section{DAFTAR PUSTAKA}

Alberca, C., Pastrana, S., Suarez-Tangil, G., \& Palmieri, P. (2016). Security analysis and exploitation of arduino devices in the internet of things. 2016 ACM International Conference on Computing Frontiers Proceedings. https://doi.org/10.1145/2903150.2911708

Arduino. (2018). ARDUINO UNO REV3.

Badamasi, Y. A. (2014). The working principle of an Arduino. Proceedings of the 11th International Conference on Electronics, Computer and Computation, ICECCO 2014. https://doi.org/10.1109/ICECCO.2014.6997578

Barrett, S. F. (2012). Arduino microcontroller: Processing for everyone. Synthesis Lectures on Digital Circuits and Systems.

https://doi.org/10.2200/S00421ED1V01Y201205DCS03 8

Galadima, A. A. (2014). Arduino as a learning tool. Proceedings of the 11th International Conference on Electronics, Computer and Computation, ICECCO 2014. https://doi.org/10.1109/ICECCO.2014.6997577

Jensen, T., \& Durham, M. (2017). Internet of things. Advancing Microelectronics.

Lele, A. (2019). Internet of things (IoT). In Smart Innovation, Systems and Technologies. https://doi.org/10.1007/978981-13-3384-2_11

Margolis, M. (2011). Arduino Cookbook. In Online.

Mattern, F., \& Floerkemeier, C. (2010). From the internet of computers to the internet of things. Lecture Notes in

Computer Science (Including Subseries Lecture Notes in Artificial Intelligence and Lecture Notes in Bioinformatics). https://doi.org/10.1007/978-3-642- 


$$
\text { 17226-7_15 }
$$

Ray, P. P. (2018). A survey on Internet of Things architectures. Journal of King Saud University Computer and Information Sciences. https://doi.org/10.1016/j.jksuci.2016.10.003

Shahid, N., \& Aneja, S. (2017). Internet of Things: Vision, application areas and research challenges. Proceedings of the International Conference on IoT in Social, Mobile, Analytics and Cloud, I-SMAC 2017. https://doi.org/10.1109/I-SMAC.2017.8058246

Sokop, Jendri Steven, Dringhuzen J. Mamahit, S. R. U. A. S. (2016). Trainer Periferal Antarmuka Berbasis

Mikrokontroler Arduino Uno. E-Journal Teknik Elektro Dan Komputer.

Tan, L., \& Wang, N. (2010). Future Internet: The Internet of Things. ICACTE 2010 - 2010 3rd International Conference on Advanced Computer Theory and Engineering, Proceedings. https://doi.org/10.1109/ICACTE.2010.5579543

Whitmore, A., Agarwal, A., \& Da Xu, L. (2015). The Internet of Things-A survey of topics and trends. Information Systems Frontiers. https://doi.org/10.1007/s10796-0149489-2

\section{PROFIL PENULIS}

Yohanes Bowo Widodo, Lahir di Jakarta 15 November 1968, sebagai Dosen Tetap Mengajar Di Fakultas Komputer Universitas MH.Thamrin Jakarta. Aktif Mengikuti Seminar, dan menulis Paper dibeberapa Jurnal, dan sebagia pnggelola dari Jurnal Teknologi Informatika \& Komputer Universitas MH.Thamrin.

Tata Sutabri, Lahir tgl 24 Oktober 1967, Sebagai Dosen Mengajar di Fakultas Komputer Universitas MH. Thamrin, Jakarta. Aktif sebagai pembicara Seminar, Menulis Paper di beberapa Conference, dan menulis buku.

Leo Faturahman, Lahir di Jakarta, 22 juli 1994, sebagi Lulusan Teknik Informatika Fakultas Komputer Universitas MH.Thamrin Jakarta. 